\title{
CONSCIÊNCIA METALINGUÍSTICA E A REPRESENTAÇÃO DA NASALIZAÇÃO NA ESCRITA DO PORTUGUÊS BRASILEIRO
}

\author{
Metalinguistic awareness and the representation \\ of nasalization in written Brazilian Portuguese
}

\author{
Fernanda Ferreira ${ }^{(1)}$, Jane Correa ${ }^{(2)}$
}

\begin{abstract}
RESUMO
Objetivo: examinar a representação da nasalização por crianças na escrita e a influência de habilidades metalinguísticas nesta representação. Métodos: crianças com escolaridade entre o $2^{\circ}$ e $5^{\circ}$ anos do ensino fundamental realizaram tarefas para avaliação de suas habilidades de análise fonológica (aliteração, subtração e manipulação de fonemas), de consciência morfológica e ditados de palavras que visavam respectivamente a avaliação do conhecimento ortográfico e particularmente o domínio de diferentes contextos e marcadores da nasalização. Resultados: a representação da nasalização para a criança é feita com relativa facilidade para a vogal nasalizada por " $n$ " antes de consoante como pelo ditongo nasal "ão" em substantivos. Porém, os contextos de ocorrência da nasalização que se referem tanto a regularidades de posição como a regularidades de natureza morfossintática apresentam dificuldade para as crianças dos anos iniciais do ensino fundamental, tornando-se relativamente mais fáceis com o progresso na escolaridade. A consciência fonológica e a consciência morfológica correlacionam-se positiva e significativamente com a marcação da nasalização. No entanto, controlada a escolaridade, apenas as tarefas de subtração e manipulação de fonemas contribuem significativamente para a representação da nasalização. Conclusão: a criança não dá um tratamento uniforme para a nasalização, entendendo que existem marcadores diferentes para os sons nasais e que estes são diferenciados segundo sua posição na palavra, embora não os usem todos de forma convencional. Diferentemente da consciência fonológica, a consciência morfológica não teve uma contribuição independente da escolaridade para a representação da nasalização.
\end{abstract}

DESCRITORES: Psicolinguística; Estudos de Linguagem; Criança

\section{INTRODUÇÃO}

O aprendizado da ortografia não é uma tarefa simples para o aprendiz, visto que nem todas as palavras são escritas exclusivamente por meio de correspondências grafofônicas regulares ${ }^{1-3}$. $O$ aprendizado da ortografia implica construir constantemente hipóteses acerca da escrita, as quais são reformuladas conforme a compreensão da criança sobre o sistema de escrita ${ }^{3-5}$. Os erros cometidos

(1) Fonoaudióloga clínica do Centro Médico Enfemed, São Gonçalo, RJ; Mestre em Psicologia pela Universidade Federal do Rio de Janeiro.

(2) Psicóloga; Professora dos Cursos de Graduação e PósGraduação em Psicologia do Instituto de Psicologia da Universidade Federal do Rio de Janeiro, UFRJ, Rio de Janeiro, RJ; Doutorado em Psicologia pela Universidade de Oxford.

Conflito de interesses: inexistente pelas crianças revelam as representações que elas fazem acerca das convenções ortográficas ${ }^{6-10}$ bem como o desenvolvimento de habilidades metalinguísticas que lhe permitam refletir e usar a linguagem de forma intencional ${ }^{11-14}$. Além da consciência fonológica, habilidade da criança para refletir e manipular conscientemente a estrutura fonológica da língua, a consciência morfológica, habilidade metalinguística relacionada à reflexão e ao uso dos aspectos morfológicos da linguagem, contribui também de forma específica para o aprendizado da ortografia ${ }^{15-17}$.

Dentre os contextos ortográficos existentes no Português Brasileiro, a escrita das vogais nasais é uma das grandes dificuldades dos aprendizes ${ }^{18}$. Há dois tipos de ocorrência envolvendo a produção de vogais nasais: a nasalização e a nasalidade 19. Na nasalização, a produção da vogal nasal é 
independente do dialeto da Língua Portuguesa. As vogais são nasalizadas devido à existência em final da sílaba de determinadas consoantes nasais (" $m$ " e "n") posicionadas imediatamente após a vogal e pelo emprego do acento gráfico til ( ), como, por exemplo, nas palavras: som, tinta e fã ${ }^{20}$. Em todos esses casos a vogal nasal pode estar em posição pretônica (chimpanzé), tônica (cinto) ou postônica (ímã). A não marcação da nasalização na escrita pode implicar a modificação do significado da palavra: cato $\mathrm{x}$ canto; seta $\mathrm{x}$ senta, por exemplo.

Diferentemente, a nasalidade ${ }^{19}$ resulta da emissão da vogal nasal devido à existência de consoantes nasais localizadas na sílaba seguinte a da vogal nasalizada, como, por exemplo, na palavra cama. A nasalidade possui também valor dialetal, pois a vogal nasal ocorreria conforme o dialeto do falante ${ }^{19}$. Assim a palavra banana, por exemplo, seria pronunciada como /bãnana/ ou /banana/ conforme o dialeto. Nestes casos, a posição pretônica da consoante nasal leva o som nasal a ser opcional, ou seja, há a assimilação da nasalidade pela vogal dependendo da localização do acento tônico na palavra.

Considerando o valor distintivo da nasalização para a escrita e a necessidade do emprego de marcadores específicos para sua representação, o presente trabalho tomou especificamente como objeto de investigação o estudo da representação da nasalização pela criança no Português do Brasil. As dificuldades na marcação da nasalização parecem envolver tanto a tendência, observada em aprendizes iniciantes, à simplificação de sílabas complexas para sílabas abertas, como evidências de que a ocorrência de vogais nasais torne o processamento fonológico mais dispendioso ${ }^{21}$. Desta forma, apesar das crianças reconhecerem a ocorrência da nasalização nas palavras, as consoantes nasais tendem a ser omitidas do segmento nasal ${ }^{22}$. Nestes casos, a nasalização passa a ser considerada pelas crianças como atributo inerente à vogal ${ }^{23}$.

A omissão da nasalização é frequente tanto na criança de desenvolvimento típico nos primeiros estágios do aprendizado da escrita, como em crianças com dificuldades específicas de aprendizagem da linguagem escrita, em pacientes neurológicos e na escrita de adultos tardiamente escolarizados ${ }^{22}$. No Português Brasileiro, a omissão da nasalização tem sido observada na escrita de aprendizes do ensino fundamental, sendo que tal omissão tende a diminuir consideravelmente ao longo da escolaridade ${ }^{24}$. A criança ao se alfabetizar trata o registro das vogais nasais de forma sistemática e estruturada, quer por sua omissão na escrita, quer pelo uso uniforme de um determinado marcador ${ }^{18}$. No último caso, a criança elegeria um determinado marcador, a consoante nasal ou o til, e o aplicaria indiscriminadamente aos sons nasais identificados na palavra ${ }^{18}$.

No Português Brasileiro a investigação acerca de como a criança representa a nasalização em sua escrita tem sido feita de forma fragmentada em termos de seus diferentes marcadores e em seus contextos de aplicação ${ }^{25}$. De maneira geral, evidências empíricas acerca da marcação da nasalização na escrita da criança estão disponíveis em investigações que tratam do domínio de regras contextuais ${ }^{24}$, ou seja, ocorrências em que a escrita de determinado fonema ou grupo de grafemas depende do contexto em que estão inseridos na palavra. Tal é o caso do emprego das letras " $m$ " e "n" como marcadores de nasalização quando posicionados antes de consoantes ${ }^{24,26}$. A representação da nasalização também tem sido examinada pela grafia das terminações "am" e "ão" ${ }^{25}$. Considerados de difícil escrita por serem similares em sua sonoridade, diferem em sua aplicação: o grupo "am" pode ser escrito em verbos no presente e no pretérito enquanto que o grupo "ão" pode ser escrito em verbos no futuro, como, por exemplo, nas conjugações andaram e andarão. Tais ocorrências têm sido investigadas procurando-se, geralmente, examinar o papel da morfologia para o domínio das convenções ortográficas.

A escolaridade parece exercer uma forte influência sobre a nasalização da vogal transmitida pelo emprego da consoante nasal na mesma sílaba ${ }^{26}$. O uso de "m" antes de "p" e "b" para nasalizar a vogal anterior apresenta dificuldades para as crianças ao longo do ensino fundamental, sendo seu emprego realizado de forma convencional em torno do 5o ano do Ensino Fundamental. O emprego de "n" antes das demais consoantes com o papel de marcador de nasalização foi considerado de mais fácil domínio. Há evidências de que por volta do $3^{\circ}$ ano as crianças possam fazer uso deste marcador de forma apropriada.

Foi observada uma determinada hierarquia no domínio da nasalização antes de consoantes, descrevendo-a em quatro etapas ${ }^{26}$. Inicialmente a nasalização não seria representada na escrita, depois as crianças tenderiam a usar o marcador "n" de modo irrestrito (ponba em vez de pomba, por exemplo). A seguir os aprendizes percebem que ambos os marcadores "m" e " $n$ " são responsáveis pela nasalização, embora o uso do " $m$ " antes de "p" e "b" não seja realizado ainda de maneira consistente. Finalmente, os aprendizes fariam o uso convencional dos marcadores nas palavras. É possível ainda que a consciência fonológica facilite a escrita de palavras cuja grafia esteja relacionada a uma regra de contexto ${ }^{14}$ como, por exemplo, o emprego 
das letras "m" e " $n$ " ao nasalizar vogais anteriores a elas.

Por outro lado, a marcação da nasalização em verbos compõe uma difícil etapa no desenvolvimento da ortografia. Os grupos "am" e "ão" são utilizados para diferenciar os tempos verbais do pretérito e futuro, respectivamente. Contudo, a informação morfossintática contida nesta representação nem sempre é evidente para os aprendizes. As crianças se confundem no momento da escrita destes tempos verbais devido à sequência final ter sonoridade semelhante. A maioria das crianças nos $2^{\circ}$ e $3^{\circ}$ anos do ensino fundamental tende a grafar com "ão" verbos com terminação em "am" ${ }^{25}$. Embora com a escolaridade, os aprendizes possam decidir de forma apropriada quando empregar as terminações "am" e "ão", ainda sim, quase metade das crianças nos $4^{\circ}$ e $5^{\circ}$ anos do ensino fundamental ainda apresentam dúvidas quanto ao seu emprego ${ }^{25}$.

Uma vez que as análises realizadas até então acerca da representação escrita da nasalização por crianças no Português Brasileiro mostram-se fragmentadas e restritas a determinados contextos ortográficos ${ }^{24-26}$, o presente trabalho tem como objetivo investigar de forma mais sistemática a marcação da nasalização por crianças ao longo do ensino fundamental, examinando a influência de habilidades metalinguísticas nesta escrita. Procurar-se-á estabelecer a dificuldade relativa no domínio das diversas formas de representação da nasalização quando comparada ao desempenho ortográfico global da criança, considerando a influência da escolaridade neste processo. Finalmente será examinado o papel da consciência fonológica e da consciência morfológica na representação escrita da nasalização pelas crianças.

\section{MÉTODOS}

Participaram deste estudo 103 crianças cursando entre o $2^{\circ}$ e $\circ 5^{\circ}$ ano do ensino fundamental. No $2^{\circ}$ ano participaram 23 alunos cujas idades variaram entre 5 anos e 10 meses e 8 anos e 5 meses (idade média $=6$ anos e 11 meses). № $3^{\circ}$ ano, 23 alunos cujas idades variaram entre 6 anos e 10 meses e 9 anos e 9 meses (idade média $=8$ anos e 3 meses). No $4^{\circ}$ ano, 30 alunos cujas idades variaram entre 8 anos e 2 meses e 11 anos e 11 meses (idade média $=9$ anos). No $5^{\circ}$ ano, 27 alunos cujas idades variaram entre 9 anos e 11 anos e 2 meses (idade média $=10$ anos).

As crianças realizaram, individualmente, em duas sessões, as tarefas de consciência metalinguistica, nesta ordem: consciência fonológica ${ }^{27}$ e consciência morfológica ${ }^{28}$. Os Ditados foram realizados posteriormente, em sala de aula, em dias diferentes, iniciando-se com o subteste de escrita do Teste de Desempenho Escolar (TDE) ${ }^{29} \mathrm{e}$ o ditado para avaliação do domínio da nasalização pelas crianças.

A avaliação da Consciência Fonológica foi realizada individualmente por meio de três tarefas desenvolvidas pelo Laboratório de Desenvolvimento Cognitivo e da Linguagem do Departamento de Psicologia da Universidade Federal de Minas Gerais ${ }^{27}$ : Aliteração, Subtração de Fonema Inicial e Manipulação de Fonema Inicial.

A Tarefa de Aliteração consistiu na identificação pela criança das duas palavras que começam com o mesmo som dentre três palavras que Ihe são apresentadas. A apresentação das palavras foi realizada em conjunto, em folha contendo figuras a elas relacionadas. $O$ aplicador nomeava cada figura, a criança repetia e, em seguida, escoIhia quais seriam as duas palavras que começariam com o mesmo som. A tarefa foi realizada em duas etapas. A primeira etapa era composta por 4 itens de prática e 12 itens de teste, onde a primeira sílaba das palavras em cada item era formada por uma consoante e uma vogal (CV). A segunda parte incluía 2 itens de prática e 10 itens de teste e a primeira sílaba era formada por duas consoantes e uma vogal (CCV). O escore máximo dessa tarefa era de 22 acertos. A instrução dada às crianças foi a seguinte: "Preste atenção: vou falar três palavras e você vai me dizer quais são as duas que começam com o mesmo som". Nos itens de prática, os acertos foram reforçados e os erros corrigidos, fato que não se repetiu nos itens de teste.

A Tarefa de Subtração de Fonema Inicial consistiu da retirada do primeiro fonema da palavra com o objetivo de formar uma nova palavra existente na língua portuguesa, por exemplo, nave sem /n/ fica ave. A tarefa era composta de 2 itens de exemplo realizados pelo examinador, 5 itens de prática e 10 palavras de teste. Os itens de exemplo eram formados por uma vogal inicial seguida de consoante e os itens de prática e de teste eram formados por consoantes seguidas de vogais. A seguinte instrução foi dada à criança: "Vamos brincar de formar palavras. Vamos fazer da seguinte forma: vou dizer a você uma palavra, você irá tirar o som do comecinho da palavra e formar uma nova palavra, assim: 'anão' sem o /a/ fica 'não'. Agora é sua vez". Assim como na tarefa de aliteração, reforçaram-se as respostas corretas e corrigiram-se as respostas erradas nos itens de prática. Não houve feedback nos itens de teste.

A Tarefa de Manipulação de Fonema Inicial consistiu em substituir o primeiro fonema da palavra por outro indicado pelo examinador e, assim, formar 
uma palavra nova existente na língua portuguesa, por exemplo, cadeira sem $/ \mathrm{k} /$ e $\mathrm{com} / \mathrm{m} /$ fica madeira. Nessa tarefa, a seguinte instrução foi dada: "Vamos brincar de formar palavras. Vamos trocar o som do comecinho da palavra, assim: 'gato' sem /g/ e com /X/ fica 'rato'. Agora é sua vez". Procedeu-se do mesmo modo como nas tarefas anteriores: acertos reforçados e erros corrigidos, não se repetindo nos itens de teste. $O$ escore máximo dessa tarefa era de 10 acertos. A tarefa é composta por três itens de prática e 10 itens de teste.

A tarefa de Consciência Morfológica ${ }^{28}$ teve como objetivo examinar a sensibilidade das crianças à morfologia derivacional. Foi solicitado à criança que realizasse a mesma derivação gramatical do exemplo dado pelo examinador, a outro par de palavras. Desta forma, se no par de palavras apresentado pelo examinador houvesse a transformação de um verbo para um adjetivo, a mesma transformação deveria ser realizada pela criança para o segundo par de palavras. A Tarefa de Analogia de Palavras foi realizada individualmente. Essa tarefa é composta por 20 itens. O escore máximo dessa tarefa é de 20 acertos. Para a realização da tarefa, a seguinte instrução foi dada, utilizando o primeiro item como treino: "Preste atenção: vou transformar uma palavra em outra e você vai fazer o mesmo, assim: 'cabeleireira' vira 'cabelo' e 'sapateiro' vira...". Não houve feedback para os erros cometidos pelas crianças durante a realização da tarefa.

Utilizou-se como instrumento de avaliação do desempenho ortográfico das crianças o subteste de escrita (ditado) do Teste de Desempenho Escolar (TDE) ${ }^{29}$. O TDE foi padronizado para a população brasileira com escolaridade entre o $2^{\circ}$ e $7^{\circ}$ anos, objetivando a avaliação das habilidades fundamentais para o desempenho escolar. $O$ ditado do subteste de escrita do TDE consistiu de 45 palavras selecionadas da Escala Ortográfica da Língua Portuguesa ${ }^{30}$ para o ensino fundamental. $O$ coeficiente de fidedignidade Alfa para o subteste de escrita do TDE, segundo o seu Manual para Aplicação e Interpretação ${ }^{29}$ é de 0.945 .

Para exame da representação da nasalização foi realizado, em sala de aula, um ditado composto por palavras selecionadas do Software de Frequência de Palavras ${ }^{31}$. As palavras eram de baixa frequência para todas as séries escolares e continham apenas um marcador de nasalização. No total, 22 palavras foram selecionadas, sendo este o número de itens que compunham a tarefa. As palavras apresentadas no ditado de palavras foram organizadas em frases e sua aplicação ocorreu do mesmo modo em que foi realizado o ditado de Desempenho Ortográfico. Para o travamento consonântico, os contextos de uso foram: a) "m" antes de "p" compridos, empacar; b) "m" antes de "b": assombrado, bambu; c) "n" antes de consoantes que não "p" ou "b": redonda, brinco; d) "m" em terminação verbal - presente do indicativo - $3^{\text {a }}$ conjugação: dormem, abrem; e) "m" em terminação verbal - presente do indicativo - 1a conjugação: guardam, corram; f) " $m$ " em terminação verbal - pretérito perfeito do indicativo - $1^{\text {a }}$ conjugação: organizaram, acordaram. Para o emprego do til forma selecionados os seguintes contextos ortográficos: a) vogal nasal (ã): rã, ímã; b) ditongo nasal "ão" em substantivos: escuridão, excursão; c) ditongo nasal "ão" em terminação verbal - futuro do presente do indicativo 1a conjugação: caberão, custarão; d) ditongo nasal "ãe"- plural de substantivos terminados em "ão": alemães, capitães; e) ditongo nasal "õe"- plural de substantivos terminados em "ão": reuniões, leões. As palavras foram apresentadas em frases e sua aplicação ocorreu do mesmo modo em que foi realizado o ditado de desempenho ortográfico

O projeto de pesquisa foi pelo Comitê de Ética em Pesquisa do Hospital Universitário Clementino Fraga Filho sob o número de protocolo 064/07, tendo todos os responsáveis pelas crianças assinado o Termo de Consentimento Livre e Esclarecido.

A análise dos resultados inclui procedimentos quantitativos e qualitativos de análise. A comparação entre a representação da nasalização pela criança e o seu desempenho ortográfico foi realizada através do emprego da Análise de Variância. Em seguida, em função dos diferentes contextos de representação da nasalização apresentados, foram descritos os perfis de desempenho das crianças por meio da Análise de Agrupamentos (Cluster Analysis). Diferenças no desempenho dos dois perfis encontrados através da Análise de Agrupamentos em relação aos diferentes contextos de representação da nasalização foram examinadas pelo emprego do Teste t-student para amostras independentes. A distribuição das crianças nos perfis em função da escolaridade foi analisada pela prova do qui-quadrado. O nível de significância estabelecido foi de $p \leq 0,05$. Foi realizada uma análise qualitativa da natureza das transgressões ortográficas relacionadas à representação da nasalização, sendo computada a frequência de ocorrência de cada categoria para os diversos contextos de representação da nasalização. Finalmente, foram realizadas correlações totais (Pearson) e parciais (controladas para escolaridade) entre o desempenho das crianças no ditado que avaliava a representação da nasalização e as diversas tarefas metalinguísticas. Novamente, o nível de significância estabelecido foi de $p \leq 0,05$. 


\section{RESULTADOS}

Com o objetivo de examinar o grau de dificuldade da representação da nasalização foi tomado como referência o desempenho ortográfico da criança avaliada pelo Teste de Desempenho Escolar (TDE) ${ }^{29}$. Para o ditado do TDE, os acertos foram computados somente no caso da produção da grafia convencional da palavra.

Para avaliar o domínio da representação da nasalização pelas crianças, foram analisadas somente as grafias no contexto específico da marcação da nasalização da tarefa de ditado elaborado para tal fim. Desta forma, os acertos no ditado seriam computados somente em relação ao fato das crianças marcarem convencionalmente a nasalização para a palavra ditada mesmo na presença de transgressões ortográficas em outros segmentos da palavra.

O desempenho das crianças nas tarefas de escrita, apresentado na Tabela 1, foi comparado através da realização de uma Análise de Variância de delineamento misto com medidas repetidas para a tarefa. Foram significantes diferenças em relação à tarefa $(F(1,97)=19,78 ; p<0,001)$, série $(F(3,97)$ $=92,24 ; p<0,001)$ e a interação entre série e tarefa $(F(3,97)=4,90 ; p=0,003)$. Análise de Variância realizada entre as séries para o ditado do TDE como da nasalização e respectivos post hoc testes (Bonferoni, todos os p's<.05) mostram um perfil distinto entre as duas tarefas em relação à diferença de desempenho em função da escolaridade. Na tarefa do TDE, observa-se diferença significativa entre o $2^{\circ}$ e $3^{\circ}$ anos, entre o $3^{\circ}$ e $4^{\circ}$ anos, mas não entre o $4^{\circ}$ e $5^{\circ}$ anos. No que concerne à representação da nasalização, observam-se diferenças significantes entre o $2^{\circ}$ e $3^{\circ}$ anos, entre o $3^{\circ}$ e o $4^{\circ}$ anos e finalmente entre o $4^{\circ}$ e $\circ 5^{\circ}$ anos indicando um avanço progressivo do conhecimento acerca da representação da nasalização ao longo das quatro séries iniciais do ensino fundamental. A comparação do desempenho entre as tarefas em cada uma das séries mostra que não há diferenças estatisticamente significantes entre a representação da nasalização e o desempenho ortográfico entre as crianças no $2^{\circ}, 3^{\circ}$ e no $5^{\circ}$ anos, mas sim para as crianças do $4^{\circ}$ ano que têm melhor desempenho na tarefa do TDE.

Dados os diferentes contextos de representação da nasalização incluídos na tarefa de ditado, decidiu-se examinar se poderiam ser descritos perfis de desempenho segundo a dificuldade relativa destes contextos. Assim, foi realizada uma análise de agrupamentos tendo como variáveis os 11 contextos ortográficos relacionados à representação da nasalização incluídos na tarefa de ditado. De tal análise resulta a formação de dois grupos que correspondem a $44 \%$ e $56 \%$ das crianças respectivamente. A Tabela 2 apresenta os escores médios das crianças em cada um dos grupos para os diferentes contextos de representação da nasalização presentes na análise. O exame de tais escores mostra que no Grupo I foram alocadas as crianças com maior número de transgressões ortográficas nos diferentes contextos de representação da nasalização. No Grupo II, foram agrupadas as crianças que obtiveram bom desempenho quanto à representação escrita da nasalização em seus diferentes contextos de uso.

A análise da diferença de desempenho dos Grupos I e II nos diferentes contextos de representação da nasalização incluídos na tarefa de ditado mostra uma diferença estatisticamente significante para todos os contextos com exceção da marcação pelo uso do til nos ditongos nasais "ão" em substantivos e na terminação de verbos no futuro do indicativo (Tabela 2).

Tabela 1 - Proporção média de acertos nas tarefas de escrita e de consciência metalinguística em função da escolaridade

\begin{tabular}{lcccccc}
\hline \multirow{2}{*}{ Série } & \multicolumn{2}{c}{ Escrita } & \multicolumn{3}{c}{ Consciência Fonológica } & Consciência \\
\cline { 2 - 6 } & $\begin{array}{c}\text { Desempenho } \\
\text { Ortográfico }\end{array}$ & $\begin{array}{c}\text { Representação } \\
\text { da Nasalização }\end{array}$ & Aliteração & Subtração & Manipulação & Morfológica \\
\hline $2^{\circ}$ ano & 0,39 & 0,36 & 0,68 & 0,68 & 0,46 & 0,44 \\
$\mathrm{n}=23$ & $(0,17)$ & $(0,15)$ & $(0,15)$ & $(0,34)$ & $(0,28)$ & $(0,14)$ \\
$3^{\circ}$ ano & 0,64 & 0,61 & 0,78 & 0,87 & 0,62 & 0,46 \\
$\mathrm{n}=23$ & $(0,15)$ & $(0,18)$ & $(0,17)$ & $(0,23)$ & $(0,21)$ & $(0,11)$ \\
$4^{\circ}$ ano & 0,90 & 0,76 & 0,89 & 0,96 & 0,84 & 0,55 \\
$\mathrm{n}=30$ & $(0,13)$ & $(0,16)$ & $(0,10)$ & $(0,07)$ & $(0,11)$ & $(0,15)$ \\
$5^{\circ}$ ano & 0,93 & 0,89 & 0,90 & 0,97 & 0,84 & 0,63 \\
$\mathrm{n}=27$ & $(0,05)$ & $(0,07)$ & $(0,09)$ & $(0,87)$ & $(0,17)$ & $(0,13)$ \\
\hline
\end{tabular}

Média; desvio-padrão entre parênteses. 
Tabela 2 - Desempenho dos grupos I e Il em cada um dos contextos de representação da nasalização

\begin{tabular}{|c|c|c|c|c|c|c|c|}
\hline & \multicolumn{2}{|c|}{ Grupo I $(n=45)$} & \multicolumn{2}{|c|}{ Grupo II $(n=58)$} & \multirow{2}{*}{ df } & \multirow{2}{*}{$\mathbf{t}$} & \multirow{2}{*}{$\mathbf{p}$} \\
\hline & M & DP & M & DP & & & \\
\hline "m" antes "p" & 0,37 & 0,31 & 0,94 & 0,16 & 101 & 12,1 & $<0,001$ \\
\hline "m" antes de "b" & 0,24 & 0,33 & 0,90 & 0,22 & 101 & 11,9 & $<0,001$ \\
\hline $\begin{array}{l}\text { "n" antes de } \\
\text { consoante }\end{array}$ & 0,82 & 0,32 & 1 & 0 & 101 & 4,2 & $<0,001$ \\
\hline $\begin{array}{l}\text { Ditongo nasal "ão" em } \\
\text { palavras }\end{array}$ & 0,93 & 0,23 & 0,98 & 0,09 & 101 & 1,5 & 0,14 \\
\hline $\begin{array}{l}\text { Ditongo nasal "ão" em } \\
\text { verbo }\end{array}$ & 0,77 & 0,38 & 0,75 & 0,30 & 101 & 25 & 0,80 \\
\hline $\begin{array}{l}\text { "m" em final de sílaba } \\
\text { de verbos - } \\
\text { conjugação presente }\end{array}$ & 0,24 & 0,33 & 0,84 & 0,30 & 101 & 9,46 & $<0,001$ \\
\hline $\begin{array}{l}\text { “m” em final de sílaba } \\
\text { de verbos - } \\
\text { conjugação pretérito }\end{array}$ & 0,30 & 0,39 & 0,78 & 0,33 & 101 & 6,86 & $<0,001$ \\
\hline $\begin{array}{l}\text { "m" em final de sílaba } \\
\text { de verbos diferente } \\
\text { de "am" }\end{array}$ & 0,50 & 0,44 & 0,95 & 0,20 & 101 & 6,89 & $<0,001$ \\
\hline Vogal nasal & 0,21 & 0,31 & 0,60 & 0,31 & 101 & 6,40 & $<0,001$ \\
\hline Ditongo nasal "õe" & 0,32 & 0,40 & 0,92 & 0,21 & 101 & 9,86 & $<0,001$ \\
\hline Ditongo nasal "ãe" & 0,12 & 0,16 & 0,71 & 0,39 & 101 & 8,69 & $<0,001$ \\
\hline
\end{tabular}

Média (M), desvio-padrão (DP), graus de liberdade (df), Teste t-student (t).

Examinando a composição dos Grupos I e II em função da escolaridade das crianças (Tabela 3), observa-se uma forte influência da escolaridade no domínio da representação da nasalização $\left(X^{2}=\right.$ $46,61, \mathrm{df}=3, \mathrm{p}<0,001)$. Cerca de $80 \%$ das crianças no Grupo I cursam o $2^{\circ}$ e o $3^{\circ}$ anos; enquanto que $83 \%$ das crianças do Grupo Il estão no $4^{\circ}$ e $5^{\circ}$ anos.

Empreendeu-se, então, uma análise qualitativa das transgressões ortográficas das crianças do Grupo I em sua tentativa de marcar (ou não) a nasalização. $O$ total de cada tipo de transgressão foi calculado sobre o total de erros cometidos pelo Grupo I em cada contexto. As transgressões das crianças em relação à representação da nasalização foram classificadas nas seguintes categorias:

Tabela 3 - Composição (\%) dos grupos I e II em função da escolaridade das crianças

\begin{tabular}{lcc}
\hline & $\begin{array}{c}\text { Grupo I } \\
(\mathbf{n = 4 5 )}\end{array}$ & $\begin{array}{c}\text { Grupo II } \\
(\mathbf{n = 5 8 )}\end{array}$ \\
\hline $1^{\circ}$ ano & 46,7 & 3,5 \\
$2^{\circ}$ ano & 33,3 & 13,8 \\
$3^{\circ}$ ano & 17,8 & 37,9 \\
$4^{\circ}$ ano & 2,2 & 44,8 \\
\hline
\end{tabular}

- Omissão do marcador de nasalização: o aprendiz escreve a palavra sem representar o marcador de nasalização - pente por pete;

- Substituição do marcador de nasalização por outro: a criança escreve a palavra substituindo os marcadores de nasalização na escrita da palavra, como trocar o marcador til ( ) pela letra n - ímã por íman;

- Emprego de mais de um marcador de nasalização: ao escrever a palavra, o aprendiz representa a nasalização através de dois marcadores - leões por leõens;

- Substituições não relacionadas à nasalização: a criança percebe a presença de um som diferente na sílaba, no caso a nasalização, mas o representa por outra letra que não as consoantes nasais $\mathrm{m}$ ou $\mathrm{n}$ - tonta por touta;

- Modificações nas palavras ${ }^{26}$ : no ato da escrita, há omissões, inversões, substituições e/ou adições de letra(s) na palavra impossibilitando o entendimento da palavra ditada, por exemplo, redonda por redoba.

A Tabela 4 apresenta a proporção média dos erros para cada um dos contextos de representação da nasalização incluídos no ditado. Observouse que a não-marcação da nasalização ocorreu em baixa frequência se comparadas a tentativas de 
Tabela 4 - Proporção média de tipos de transgressões para cada um dos contextos de representação da nasalização

\begin{tabular}{|c|c|c|c|c|c|}
\hline Contextos & $\begin{array}{l}\text { Omissão do } \\
\text { marcador }\end{array}$ & $\begin{array}{l}\text { Marcador } \\
\text { diferente }\end{array}$ & $\begin{array}{l}\text { Mais de um } \\
\text { marcador }\end{array}$ & $\begin{array}{l}\text { Marcador } \\
\text { não } \\
\text { relacionado }\end{array}$ & $\begin{array}{l}\text { Modificação } \\
\text { nas palavras }\end{array}$ \\
\hline "m" antes de "p" & 0,04 & 0,94 & 0 & 0,02 & 0 \\
\hline "m" antes de "b" & 0,19 & 0,74 & 0 & 0,02 & 0,05 \\
\hline $\begin{array}{l}\text { "n" antes de } \\
\text { consoantes que } \\
\text { não p ou b }\end{array}$ & 0,63 & 0,06 & 0 & 0,31 & 0 \\
\hline $\begin{array}{l}\text { “m” em terminação } \\
\text { verbal - presente - } \\
3^{\text {a }} \text {. conjugação }\end{array}$ & 0,11 & 0,77 & 0 & 0,07 & 0,05 \\
\hline $\begin{array}{l}\text { "m" em terminação } \\
\text { verbal - presente - } \\
\text { 1a. conjugação }\end{array}$ & 0,03 & 0,74 & 0 & 0,21 & 0,02 \\
\hline $\begin{array}{l}\text { "m” em terminação } \\
\text { verbal - pretérito - } \\
\text { 1‥ conjugação }\end{array}$ & 0,01 & 0,88 & 0 & 0,01 & 0,09 \\
\hline vogal nasal (ã) & 0,28 & 0,49 & 0,08 & 0,13 & 0,02 \\
\hline $\begin{array}{l}\text { ditongo nasal "ão" - } \\
\text { substantivos } \\
\text { ditongo nasal "ão" }\end{array}$ & 0 & 0,4 & 0 & 0 & 0,6 \\
\hline $\begin{array}{l}\text { em verbo - futuro - } \\
\text { 1a. conjugação } \\
\text { ditongo nasal "ãe"- }\end{array}$ & 0 & 0,78 & 0 & 0,17 & 0,05 \\
\hline $\begin{array}{l}\text { plural de } \\
\text { substantivos } \\
\text { terminados em "ão" }\end{array}$ & 0,15 & 0,12 & 0 & 0,67 & 0,06 \\
\hline $\begin{array}{l}\text { ditongo nasal "õe"- } \\
\text { plural de } \\
\text { substantivos } \\
\text { terminados em "ão" }\end{array}$ & 0,12 & 0,08 & 0 & 0,77 & 0,03 \\
\hline
\end{tabular}

marcação da nasalização, seja por representações da nasalização apropriadas a outros contextos, como por utilização de marcadores não-convencionados para a escrita do som nasal.

Foi examinada, então, a relação entre as habilidades metalinguísticas e o domínio da representação da nasalização através da análise dos coeficientes de correlação (Pearson) entre os escores das crianças no ditado e nas tarefas relacionadas à avaliação da consciência fonológica (aliteração, subtração e manipulação de fonemas) e da consciência morfológica. A Tabela 4 mostra que o domínio da marcação da nasalização está positiva e estatisticamente correlacionado com as habilidades de consciência fonológica como com a consciência morfológica. Desta forma, crianças com maior domínio da representação da nasalização são aquelas que também possuem habilidades metalinguísticas mais desenvolvidas. Entretanto, conforme mostram as Tabelas 1 e 3, os maiores escores nas tarefas de ditado são obtidos por crianças com mais escolaridade. Assim, foi analisada a relação entre os escores das crianças no ditado e as tarefas de natureza metalinguística, realizando o controle sobre a influência da escolaridade. A Tabela 5 apresenta a correlação parcial entre os escores no ditado e nas tarefas relacionadas à avaliação da consciência metalinguistica. Uma vez controlado o efeito da escolaridade, observam-se somente correlações positivas e estatisticamente significantes entre o desempenho das crianças no ditado e nas tarefas de subtração e manipulação de fonemas. 
Tabela 5 - Correlações totais e parciais entre representação da nasalização e habilidades metalinguísticas (correlações parciais controladas para escolaridade)

\begin{tabular}{lcc}
\hline & \multicolumn{2}{c}{ Ditado - Nasalização } \\
\cline { 2 - 3 } & Correlação & Correlação Parcial \\
\hline Consciência Fonológica & & 0,05 \\
Aliteração & $0,46^{* *}$ & $0,20^{\star}$ \\
Subtração & $0,47^{* *}$ & $0,23^{\star}$ \\
Manipulação & $0,58^{* *}$ & 0,05 \\
Consciência Morfológica & $0,41^{* *}$ & \\
\hline
\end{tabular}

Correlação $\left(\right.$ Pearson) ${ }^{*} \mathrm{p} \leq .05 ;{ }^{*} \mathrm{p} \leq .01$

\section{DISCUSSÃO}

A análise da escrita pelas crianças das palavras que lhes foram ditadas mostra que, no domínio das convenções ortográficas avaliado pelo Teste de Desempenho Escolar (TDE), há uma diferenciação entre o primeiro ( $2^{\circ}$ e $3^{\circ}$ anos) e o segundo ciclos ( $4^{\circ}$ e $5^{\circ}$ anos) do ensino fundamental. A grafia convencional das palavras ainda é uma tarefa de relativa dificuldade para as crianças cursando o $1^{\circ}$ ciclo do ensino fundamental. $\mathrm{O} 3^{\circ}$ ano parece ser um ponto de inflexão em termos do conhecimento ortográfico da criança. Em termos gerais, a criança, nesta etapa de sua escolaridade, conseguiria resolver com relativa facilidade grande parte dos desafios colocados pelas convenções ortográficas apresentadas, não havendo, inclusive, diferenças significantes do seu desempenho em relação ao das crianças cursando a série seguinte. Por outro lado, a representação da nasalização apresenta uma dificuldade em particular, sendo que seu aprendizado ocorre de forma progressiva ao longo do $1^{\circ}$ e $2^{\circ}$ ciclos do Ensino Fundamental. A dificuldade relativamente maior em representar a nasalização parece ocorrer porque esta marcação não possui uma correspondência grafema-fonema específica ${ }^{23}$.

A nasalização no Português traz para a criança certa complexidade em sua representação ${ }^{18}$. Embora a produção da vogal nasal por travamento consonântico ocorra em uma série de outras línguas alfabéticas com o inglês e o francês ${ }^{21}$, por exemplo, a existência do ditongo nasal "ão" é uma particularidade do Português. Os resultados da presente investigação mostram que a representação da nasalização é feita com relativa facilidade quando da vogal nasalizada por " $n$ " antes de consoante como pelo ditongo nasal "ão" em substantivos, mesmo para as crianças no $1^{\circ}$ ciclo do ensino fundamental ( $2^{\circ}$ e $3^{\circ}$ anos). Neste sentido, as crianças, mesmo nos anos iniciais de seu aprendizado da escrita, mostram-se bastante sensíveis às particularidades da língua ${ }^{5,7}$.
Por outro lado, os contextos de ocorrência da nasalização que se referem tanto a regularidades de posição ("m" antes de "p" e "b", por exemplo) como a regularidades de natureza morfossintática (como nasalização em desinências verbais no presente e no pretérito) apresentam dificuldade para as crianças dos anos iniciais do ensino fundamental ${ }^{25,26}$. Tais representações tornam-se relativamente mais fáceis com o progresso na escolaridade ${ }^{24,26}$.

De acordo com os resultados encontrados, observou-se que o aprendiz percebe a existência do som nasal na sílaba. Embora a omissão da marcação da nasalização ocorra na escrita da criança, tais ocorrências são pouco frequentes em relação às tentativas de marcação. Entretanto, apesar de identificar a nasalização, a sua representação não é realizada pela criança de forma convencional a não ser nos casos de representação do ditongo "ão" em substantivos como do emprego da consoante " $n$ ", bastante distintivos e canônicos em relação à representação da nasalização. Tais marcadores são usados em outros contextos na tentativa de marcar o som nasal, porém não indistintamente. $O$ ditongo "ão" é usado para a representação do ditongo átono - "am". O uso da consoante nasal "n", por sua frequência de uso ${ }^{26}$, é escolhida para a marcação da vogal nasal em meio de palavra. O "m" em fim de palavra, desde que não envolva o som "ão".

Além da escolaridade, avaliou-se ainda o papel das habilidades metalinguísticas para a representação da nasalização. A consciência fonológica e a consciência morfológica correlacionam-se significativamente com a representação da nasalização. Porém, depois de controlada a influência da escolaridade, somente as tarefas de análise fonológica relacionadas à subtração e à manipulação de fonemas correlacionaram-se significantemente com a representação da nasalização. Supõe-se, então, que, em função da relativa regularidade do Português, a criança empregaria primordialmente estratégias de escrita baseadas na correspondência grafofonêmica ${ }^{19,20}$. Isto faria com que a 
criança recorresse primordialmente ao emprego da análise fonológica para a solução dos obstáculos que encontra na escrita. No caso da nasalização, observa-se que a sua marcação pode ser resolvida em vários vocábulos quando observados: a) a natureza do segmento nasal (distinção entre vogais e ditongos); b) a tonicidade; e c) a ocorrência da posição do segmento nasal. Tais contextos irão requerer o emprego de habilidades de análise fonológica pelas crianças.

Entretanto, em alguns contextos o segmento nasal contém informações de natureza morfológica, principalmente do ponto de vista da morfologia derivacional. Desta forma, habilidades de natureza morfológica podem influenciar o domínio desta representação pelas crianças. Porém, os resultados dessa pesquisa mostram que a consciência morfológica não teve, para a representação da nasalização, uma contribuição independente do nível de escolaridade das crianças. Tais resultados relativizam a importância da consciência morfológica para o desempenho ortográfico no Português Brasileiro ${ }^{15,16}$. Porém, uma vez que a consciência morfológica não é uma habilidade unitária, pode ser que seja necessária a avaliação desta habilidade por outras tarefas em que possam fazer referência tanto ao processamento morfológico em relação à derivação quanto à flexão verbal ou nominal ${ }^{32}$. Estudos futuros são imprescindíveis, particularmente no que se refere ao papel da escolaridade, da consciência fonológica e da consciência morfológica na marcação da nasalização em contextos específicos, como, por exemplo, "m" antes de "p" e "b" e segmento nasal em verbos no presente e pretérito.

A descrição e compreensão detalhada da representação da nasalização pela criança são importantes para que professores e profissionais da área de saúde, como fonoaudiólogos, possam planejar sua ação pedagógica ou terapêutica, respectivamente.

\section{CONCLUSÂO}

Contrariamente a hipótese de que haja por parte da criança um tratamento uniforme para a nasalização, observou-se que desde cedo, a criança parece ter o entendimento de que existem marcadores diferentes para os sons nasais, embora não os empregue de forma convencional nos seus diversos contextos de ocorrência.

Diferentemente da consciência fonológica, a consciência morfológica não parece ter uma contribuição independente da escolaridade para a representação da nasalização.

\section{AGRADECIMENTOS}

O presente artigo deriva da dissertação de mestrado apresentada ao Programa de Pós-Graduação em Psicologia da UFRJ pela primeira autora sob orientação da segunda autora. Agradecemos a escola pelo apoio e acolhida; aos responsáveis pela confiança em nosso trabalho e às crianças pelo muito que generosamente nos ensinaram sobre sua escrita. Nossos agradecimentos ainda à Faperj - Cientistas do Nosso Estado e ao CNPq.

\begin{abstract}
Purpose: to analyze children's representation of nasalization in spelling and the effect of their metalinguistic skills on such representation. Methods: $2^{\text {nd }}-5^{\text {th }}$ graders were given tasks in order to evaluate phonological skills (alliteration, phoneme deletion and spoonerism), morphological awareness and their spelling, in particular, their understanding of the different ways regarding nasal sounds' representation and their usage contexts. Results: it was relatively easy for children to represent nasal cluster (vowel $+n$ ) and the nasal diphthong (ão) in nouns. However, they found it difficult to deal with contextual and morphological rules in order to represent nasal segments. Significance and positive correlations were observed between both phonological and morphological awareness and the spelling of nasal sounds. However, after controlling the schooling, only phonological tasks (deletion and spoonerism) had a significant contribution for nasalization representation. Conclusion: children do not usually have a uniform manner to represent nasal sounds. They understand that nasalization has different ways to be represented and usage contexts, although they are not able to use all of them appropriately. Differently from phonological skills, morphological awareness did not show an independent contribution to the representation of nasalization after controlling the schooling.
\end{abstract}

KEYWORDS: Psycholinguistics; Language Arts; Child 


\section{REFERÊNCIAS}

1. Bryant $P$, Nunes $T$. Morphemes, spelling and development: comments on "The timing and mechanisms of children's use of morphological information in spelling" by S. Pacton and H. Deacon. Cognitiv Dev. 2008; 23(3):360-9.

2. Meireles ES, Correa J. A relação da tarefa de erro intencional com o desempenho ortográfico da criança considerados os aspectos morfossintáticos e contextuais da língua portuguesa. Estud Psicol. 2006; 11(1):35-43.

3. Treiman R, Kessler B. Spelling as statistical learning: using consonantal context to spell vowels. J Educ Psychol. 2006; 98(3):642-52.

4. Davis C, Bryant P. Causal connections in the acquisition of an orthographic rule: a test of Uta Frith's developmental hypothesis. J Child Psychol Psychiatr. 2006; 47(8):849-56.

5. Bowman $M$, Treiman $R$. Are young children logographic readers and spellers? Sci Stud Read. 2008; 12(2):153-70.

6. Critten S, Pine K, Steffler D. Spelling development in young children: a case of representational redescription? J Educ Psychol. 2007; 99(1):207-20.

7. Correa J, Maclean M, Meireles ES, Lopes TC, Glockling D. Using spelling skills in Brazilian Portuguese and English. J Port Linguist. 2007; 6(2):61-82.

8. Vieira RMR, Grosso PMP, Zorzi JL, Chiappetta ALML. Estudos comparativos sobre a influência da leitura nos erros da escrita entre meninos e meninas de quarta série. Rev. CEFAC. 2006; 8(3):281-8.

9. Zorzi JL, Ciasca SM. Caracterização dos erros ortográficos em crianças com transtornos de aprendizagem. Rev. CEFAC. 2008; 10(3):321-31. dx.doi.org/10.1590/S1516-18462008000300007

10. Bernstein SE. Phonology, decoding, and lexical compensation in vowel spelling errors made by children with dyslexia. Read Writ. 2009; 22(3):307-31.

11. Mota MMPE, Silva K. Consciência morfológica e desenvolvimento ortográfico: um estudo exploratório. Psicol Pesq. 2007; 1(2):86-92.

12. Chliounaki K, Bryant $P$. How children learn about morphological spelling rules. Child Dev. 2007; 78(4):1360-73.

13. Alcock K, Ngorosho D. Learning to spell and learning phonology: the spelling of consonant clusters in Kiswahili. Read Writ. 2007; 20(7):643-70.

14. Rego LLB, Buarque LL. Consciência sintática, consciência fonológica e aquisição de regras ortográficas. Psicol Reflex Crit. 1997; 10(2):199-217.
15. Mota MMPE, Aníbal L, Lima S. A morfologia derivacional contribui para a leitura e escrita em português? Psicol Reflex Crit. 2008; 21(2):311-8.

16. Nagy W, Berninger VW, AbbottRD. Contributions of morphology beyond phonology to literacy outcomes of upper elementary and middle-school students. J Educ Psychol. 2006; 98(1):134-47.

17. Deacon SH, Bryant PE. Getting to the root: young writers' sensitivity to the role of root morphemes in the spelling of inflected and derived words. J Child Lang. 2006; 33(2):401-17.

18. Simões D. Considerações sobre a fala e a escrita. São Paulo: Parábola Editorial; 2006.

19. Silva CT. Fonética e fonologia do português: roteiro de estudos e guia de exercícios. 3. ed. São Paulo: Contexto; 2002.

20. Mateus MHM. Sobre a natureza fonológica da ortografia portuguesa. Est Língua. 2006; 3(1):159-80.

21. Magnan A, Bianchéri $P$. Le traitement des voyelles nasalisées et des groupes consonantiques par l'apprenti-lecteur francophone. Int J Psychol. 2001; 36(5):301-13.

22. Snowling MJ. The spelling of nasal clusters by dyslexic and normal children. Spelling Prog Bull. 1982; 22(1):13-8.

23. Treiman R, Zukowsky A, Richmond-Welty ED. What happened to the " $n$ " of sink? Children's spellings of final consonant clusters. Cognition. 1995; 55(1):1-38.

24. Carraher TN. Explorações sobre o desenvolvimento da competência em ortografia em português. Psicol Teor Pesq. 1985; 1(3):269-85.

25. Zorzi JL. Aprendizagem e distúrbios da linguagem escrita: questões clínicas e educacionais. Porto Alegre: Artmed; 2003.

26. Meireles ES, Correa J. Regras contextuais e morfossintáticas na aquisição da ortografia da língua portuguesa por criança. Psicol Teor Pesq. 2005; 21(1):77-84.

27. Martins CC, Michallick-Triginelli MF. Codificação fonológica e ortográfica na dislexia de desenvolvimento: evidência de um estudo de caso. Arq Bras Psicol. 2009; 61(1):153-61.

28. Correa J, Dockrell JE. Unconventional word segmentation in Brazilian children's early text production. Read Writ. 2007; 20(8):815-31.

29. Stein LM. TDE - teste de desempenho escolar. São Paulo: Casa do Psicólogo; 1994.

30. Tasca M, Poersch JM, organizadores. Suportes linguísticos para a alfabetização. Porto Alegre: Sagra; 1986. 
31. Pinheiro AMV. Contagem de frequência de ocorrência de palavras expostas a crianças na faixa pré-escolar e séries iniciais do $1^{\circ}$ grau. São Paulo: Associação Brasileira de Dislexia; 1996.
32. Deacon $\mathrm{SH}$, Bryant $\mathrm{P}$. What young children do and do not know about the spelling of inflections and derivations. Dev Sci. 2005; 8(6):583-94.

RECEBIDO EM: 01/06/2009

ACEITO EM: 04/10/2009

Endereço para correspondência:

Fernanda Ferreira

Rua Jornalista Ary Guanabara, 363

Niteroi - RJ

CEP: $24340-200$

E-mail: fgafernanda@gmail.com

Rev. CEFAC. 2010 Jan-Fev; 12(1):40-50 